\title{
La influencia de las nuevas tecnologías en la documentación del proceso penal español
}

\author{
The influence of new technologies in the Spanish criminal procedure \\ documentation
}
Maria Dolores Ramirez Benavente ${ }^{1}$
Universidad de Córdoba - España
d22rabem@uco.es
http://orcid.org/0000-0002-5456-8289

\begin{abstract}
RESUMEN: El presente artículo tiene como objetivo analizar la incidencia que las nuevas tecnologías han tenido en la documentación procesal, especialmente, en el acta del juicio oral. Así mismo, se examinará la incidencia de estas tecnologías en el derecho al recurso de las partes y su conexión con los derechos fundamentales de carácter procesal. Con carácter ilustrativo se plantea el problema del acta defectuosa, como causa de la nulidad del proceso judicial y posible supuesto de responsabilidad patrimonial de la Administración.
\end{abstract}

Palabras clave: Nuevas Tecnologías; derecho al recurso; acta defectuosa; nulidad; responsabilidad patrimonial.

ABSTRACT: The present work aims to analyse the impact of the new technologies in the procedural documentation, specially, in the act of oral trial. However, it will review the effects of these technologies in the right to appeal and its relation with other fundamental procedural rights. With an illustrative intention, it will be present the problem of the defective act, as a cause of nullity of the legal trial and possible case study of patrimonial responsibility from the public administration.

KEYWORDs: New Technologies; right to appeal; defective act; nullity; patrimonial responsibility.

1 Doctoranda en Derecho Procesal en la Universidad de Córdoba - España. Colaboradora Honoraria de Derecho Procesal en la Universidad de Córdoba. 


\section{Nuevas tecnologías y Administración de Justicia.}

El avance tecnológico incide marcadamente en el modo en el que el ser humano se relaciona con el entorno; y esta afirmación es válida no sólo para el medio ambiente sino para todo entorno humano, incluida la Administración de Justicia. Ciertamente, la revolución tecnológica del último siglo ha transformado y continuará transformando las relaciones del ciudadano con la Administración de Justicia, al igual que se ha modificado considerablemente la praxis propia del conjunto de profesionales jurídicos.

Esta nueva concepción funcional y tecnológica de la Administración de Justicia comenzó en nuestro país en el año 2000 a raíz de la promulgación de la renovada Ley de Enjuiciamiento Civil (Ley 1/2000), la cual inauguró un iter legislativo dirigido a la modernización de la justicia que concluyó finalmente con la promulgación de la Ley 18/2011 de 5 julio reguladora del uso de las tecnologías de la información y comunicación en la Administración de Justicia ${ }^{2}$. Esta última ley tenía como objetivo fundamental la implantación de las nuevas tecnologías en la práctica profesional de los funcionarios de justicia y avanzar progresivamente para la plena tramitación electrónica de los procesos judiciales ${ }^{3}$. En verdade, el avance en la informatización de la Administración ha sido considerable, aunque algo desigual territorialmente. El proceso comenzó con la mejora de los instrumentos de comunicación y obtención de información, también mediante el establecimiento de una conectividad en tiempo real entre las diferentes administraciones públicas; pero aún quedaría camino por recorrer en las

2 Este recorrido principia, como se ha escrito con la Ley $1 / 200$, a la que seguirán la ley 15/2003 reguladora del régimen retributivo de las carreras judicial y fiscal; la ley 11/2007 de acceso electrónico de los ciudadanos a los servicios públicos; el Plan de Acción E-justicia del año 2008 de orden europeo; la ley 13/2009 de reforma de la legislación procesal para la implantación de la nueva oficina judicial; y, finalmente, la Ley 18/2011 reguladora del uso de las tecnologías de la información y comunicación en la Administración de Justicia.

3 LOMBARDÍA VILLALBA, A., "Nuevas Tecnologías y Administración de Justicia”, Foro de Actualidad Uría Menéndez, n. 30, (2011), p. 63. 
relaciones de comunicación con procuradores y abogados ${ }^{4}$. Este escollo fue superado con la introducción del sistema de comunicación jurídica LEXNET, el cual, a pesar de sus numerosos fallos de funcionamiento y seguridad, ha supuesto importantes beneficios en el funcionamiento de la Justicia y ha contribuido a agilizar la práctica jurídica de procuradores, abogados, notarios, registradores, fiscales y jueces. Todo este proceso se ha traducido en una mayor eficiencia en el tratamiento de los casos, un ahorro de tiempo, una disminución de los costes y un más fácil acceso a una justicia de mayor calidad ${ }^{5}$.

\section{InfLUENCIA de LAS NUEVAS TECNOLOGías EN LA DOCUMENTACIÓN DEL JUICIO.}

La necesidad de documentar los actos del juicio oral tiene su origen en la Decretal de probationibus que Inocencio III dio en el Concilio de Letrán de 1215, claro que se trata de una actividad documentadora muy diferente de la actual; pero que comparte con esta la finalidad de garantizar la capacidad de recurrir de los sujetos del proceso. Su existencia es incluso anterior en España a la aparición de los escribanos y ya se puede encontrar en los textos del Liber Iudiciorum ${ }^{6}$. Lo característico de esta primera documentación procesal es que se exigía la presencia del juez o una persona de su confianza como garantía de la veracidad de lo declarado o recogido en esta documentación, lo que supone un matiz interesante; pues, la valía del documento resulta de su autoría y no tanto de su contenido. De modo que ya, desde el inicio, se da prioridad a la

4 JIMÉNEZ ASENSIO, R., "Administración de Justicia y Nuevas Tecnologías: líneas de evolución de un proceso abierto", Nuevas Políticas Públicas: Anuario multidisciplinar la modernización de las Administraciones Públicas, n. 1, (2005), p. 79.

5 MEDINA MORALES, D., "Administrar justicia en la era tecnológica”, Persona y Derecho, n. 78, (2018), pp. 176-177.

6 SÁEZ GONZÁLEZ, J., "Una nota histórica: primeras noticias sobre la actividad de documentación procesal en nuestro derecho", Justicia, n. 95, (1993), pp. 121-122. 
condición de garante de quien redacta el documento, lo que posibilita el ejercicio del derecho a recurrir ${ }^{7}$.

Tradicionalmente, la documentación del acta ha sido siempre escrita pero ya en la LO 6/1985 del Poder Judicial (en adelante LOPJ), contemplaba en su artículo 230 la utilización de cualesquiera medios técnicos de documentación y reproducción siempre que ofreciesen garantía de su autenticidad. Poco después, la Ley 16/1994 reformó este artículo 230 para establecer que, en el desarrollo de la actividad y ejercicio de sus funciones, los juzgados y tribunales pueden servirse de "cualesquiera medios técnicos, electrónicos, informáticos y telemáticos”. Ahora bien, no fue hasta la entrada en vigor de la Ley 1/2000 de Enjuiciamiento Civil, cuando se abrió la posibilidad por primera vez de una documentación procesal extraña al papel, concretamente en sus artículos 146, 147 y 187 que impusieron como preceptiva la documentación de las actuaciones orales mediante sistemas audiovisuales; sin perjuicio de la obligación de levantar acta sucinta por parte del secretario judicial, así como la posibilidad de unir a los autos una transcripción de lo grabado en los medios de reproducción de imagen y sonido ${ }^{8}$.

Rápidamente, la documentación audiovisual del juicio oral se extendió a otros órdenes jurisdiccionales y finalmente la ley 13/2009, de reforma de la legislación procesal para la implantación de la nueva oficina judicial, sancionó con carácter obligatorio la grabación audiovisual de juicios y vistas en todas las leyes procesales (civil, penal, laboral y contencioso administrativa) lo que fue recibido por la doctrina y por la comunidad jurídica como un avance en las garantías procesales del justiciable?

Lo cierto es que, excepciones a parte, la posibilidad de una grabación audiovisual del acto del juicio oral supone un avance a fin

7 SÁEZ GONZALEZ, J., "Propuestas sobre los contenidos de la documentación audiovisual de los juicios orales. Papel del secretario judicial”, Revista vasca de derecho procesal y arbitraje, n. XXI.1, (2009), pp. 48-49.

8 AGUILERA MORALES, M., GARCÍA COUSO, S., "Las grabaciones defectuosas o fallidas de las vistas y juicio: transcendencia procesal y constitucional", Nuevas tecnologías y derechos fundamentales en el proceso, Cizur Menor, Aranzadi, 2017, p. 238.

$9 \quad$ Ibidem, p. 239. 
de garantizar el principio de oralidad y de evitar su desnaturalización mediante la escrituración excesiva del proceso. Igualmente, la grabación audiovisual permite una mejor realización del principio de inmediación, pues permite la visualización directa del acto del juicio por parte del juzgador en segunda instancia. En consecuencia, si se acepta que la finalidad de la documentación procesal del juicio oral es constituir la base para un efectivo ejercicio del derecho a recurrir no cabe duda de que los medios audiovisuales potencian la oralidad y la inmediación en segunda instancia ${ }^{10}$.

Con anterioridad a examinar la naturaleza del acta audiovisual, conviene recordar los elementos objetivos y subjetivos de la antigua acta escrita con la finalidad de esclarecer si realmente este tránsito tecnológico ha servido para mejorar las garantías del proceso o por el contrario presenta más inconvenientes que ventajas. El primer elemento que destacar es la autoría del acta escrita, que corresponde con exclusividad al secretario judicial, única autoridad con potestad documentadora (art. $281 \mathrm{LOPJ})^{11}$. En lo referente a la forma del documento del acta, deben señalarse los siguientes requisitos: a) la grafía, que debe recoger el significado de las actuaciones tanto para su autor como para sus destinatarios; b) la expresividad, que exige que el documento esté redactado de un modo objetivamente comprensible; c) recognoscibilidad, que impone que lo recogido en el documento sea tenido por cierto para todos; $\mathrm{y}$ d) el alcance del acta debe ser lo más omnicomprensivo posible, es decir, el secretario no solo refleja las expresiones o declaraciones de los sujetos del proceso; sino que documenta la realidad que observa, recogiendo todo cuanto le sea posible ${ }^{12}$. Respecto de los elementos materiales del acta escrita se pueden enumerar del siguiente modo: papel y escritura, idioma castellano, firma, sello, visto bueno y conformidad del secretario ${ }^{13}$. Finalmente, los principios que informan la documentación procesal del acta son los

10 SÁNCHEZ PARELLADA, J., "El acta del juicio oral en el proceso penal y las nuevas tecnologías”, Actualidad penal, n. 1, (2003), pp. 357-359.

11 SÁEZ GONZÁLEZ, J., El acta del juicio oral en el proceso penal, Barcelona, Bosch, 1996, pp. 139-141.

12 Ibidem, pp. 117-121.

13 Ibidem, pp. 122-126. 
siguientes: fidelidad, exactitud, autoría, perdurabilidad, solemnidad, carácter probatorio y público ${ }^{14}$.

Los aspectos positivos de este modo de documentación escrita del acta están ligados directamente a la figura del secretario judicial como garante de la legalidad del proceso. Siendo así, la escrituración del proceso judicial garantiza la inmediatez del secretario judicial y el carácter instrumental del acta para el ejercicio del derecho de defensa de las partes. Gracias a la intervención del secretario, este documento alcanza pleno valor probatorio en tanto documento público que debe respetarse en su integridad en instancias sucesivas. El contrapunto es que, como toda escritura, supone un lenguaje de signos cuya relación semiótica (signo-significado) exige un esfuerzo intelectual por parte de sus destinatarios y es posible que no siempre lo comprendido por estos se corresponda con la intención o el sentido declarado por el secretario en el acta.

La introducción del acta videográfica no responde a un capricho de innovación, sino que mejora la forma de documentar el acto de la vista y con ello, se otorga a los ciudadanos una más efectiva garantía de sus derechos en el proceso ${ }^{15}$. Debe señalarse que, más allá de los elementos subjetivos, formales y materiales del acta, los principios que informan esta documentación procesal se ven más y mejor protegidos mediante la grabación audiovisual de las actuaciones. Obviamente, el documento audiovisual refleja con mayor fidelidad y exactitud el acto del juicio; también, es cierto que la perdurabilidad de la grabación es mayor que la del documento escrito. Finalmente, siempre que la grabación esté supervisada o presidida por el secretario judicial, no cabrán sospechas acerca de su carácter solemne, probatorio y público.

Por estas razones, progresivamente se ha ido generalizando la introducción de los medios audiovisuales en la documentación procesal y hoy se prima la utilización de los modernos sistemas de documentación frente a los tradicionales; incluso la Ley Orgánica 7/2015 de reforma de la

14 Ibidem, pp. 139-132.

15 Ibidem, p. 270. 
LOPJ en su artículo 230.3 ha prohibido la transcripción de las actuaciones grabadas por medios audiovisuales ${ }^{16}$.

Esta evolución puede observarse sintéticamente del siguiente modo: a) una situación inicial en la que primaba el carácter escrito de la documentación procesal y del acta en particular; b) una situación intermedia en la que existía una complementariedad entre la escrituración y grabación audiovisual de los actos del juicio oral ${ }^{17}$ y c) la situación actual en la que existe una clara primacía del acta videográfica y solo cuando sea imposible su uso se impone la forma escrita. Este cambio tampoco ha sido indiferente para la figura del secretario judicial, quien inicialmente estaba siempre presente en todas las actuaciones procesales del juicio oral y que hoy le es suficiente acreditar electrónicamente la autoría del acta para su validez, sin necesidad de su presencia en la sala ${ }^{18}$.

\section{Garantías procesales de la segunda instancia penal. El DERECHO FUNDAMENTAL AL RECURSO.}

Aunque los recursos cumplen una clara función instrumental en el ordenamiento jurídico, pues contribuyen a corregir los errores judiciales y a completar el mandato contenido en las sentencias, no parece tan claro si el ejercicio de los recursos por parte de los justiciables puede o no considerarse un derecho fundamental en la legislación española. Inicialmente no es así, porque el derecho al recurso no está incluido expresamente entre los derechos fundamentales del Capítulo Segundo del Título I y, además, las dispersas menciones de la jurisprudencia constitucional al respecto tampoco lo avalaba ${ }^{19}$. La doctrina constitucional

16 AGUILERA MORALES, M., GARCÍA COUSO, S., "Las grabaciones defectuosas o fallidas de las vistas...", op. cit., pp. 241-243.

SÁEZ GONZÁLEZ, J., El acta del juicio oral..., op. cit., pp. 259-270.

18 AGUILERA MORALES, M., GARCÍA COUSO, S., "Las grabaciones defectuosas o fallidas de las vistas...", op. cit., p. 244. "La grabación en soporte digital constituye el habitual medio con que, hoy día, se documentan las actuaciones orales del proceso".

19 CALDERÓN CUADRADO, M.P., La segunda instancia penal, Cizur Menor, Aranzadi, 2005, p. 161. 
era clara al respecto señalando que, únicamente cuando el legislador instaura un medio de impugnación se entenderá el recurso contenido dentro del derecho a la tutela judicial efectiva ${ }^{20}$.

Ahora bien, esta libertad del legislador para establecer los medios de impugnación no se puede predicar en el orden penal, ya que desde la suscripción por España en 1977 del Pacto Internacional de Derechos Civiles y Políticos y del Convenio Europeo de Derecho Humanos (ratificado en 1979) y el encaje constitucional de ambos acuerdos en las previsiones del artículo 10. 2 de la Constitución Española (en adelante CE) otorga a la persona declarada culpable de un delito el derecho a que el fallo condenatorio y la pena que se le haya impuesto sean sometidos a un tribunal superior conforme a lo prescrito en la ley. Aquí se encontraría formulado el derecho al recurso, que tendría carácter fundamental en virtud del artículo 10.2 CE, pero a pesar de esto aun debe cuestionarse el fundamento de este. La dogmática penalista se encuentra dividida y aunque todos coinciden en adscribir este derecho al texto del artículo $24 \mathrm{CE}$, hay quienes consideran que se trata de una manifestación del derecho a la tutela judicial efectiva ${ }^{21}$; otros que consideran que se trata de un mandato implícito en la exigencia de un proceso con las debidas garantías ${ }^{22}$; y también quienes lo proyectan en el derecho de defensa ${ }^{23}$.

Se considera que estas visiones no son incompatibles entre sí, y como expresamente señala Yáñez Velasco: "Es escaso el sentido de buscar una ubicación unívoca del derecho al recurso, en uno u otro apartado del artículo $24 \mathrm{CE}$, cuando ambos se relacionan de forma tan profunda, impidiendo su consideración estanca. Antes bien, por su carácter implícito, más que ningún otro derecho procesal, está impregnado en multitud de lugares en el texto constitucional y en la propia filosofía rectora de este,

20 SSTC 59/1984 de 10 de mayo; 102/1984 de 12 de noviembre; 109/1987 de 29 de junio; 5/1988 de 21 de enero; 10/1988 de 7 de julio.

21 YÁÑEZ VELASCO, R., Derecho al recurso en el proceso penal, Valencia, Tirant lo Blanch, 2001, pp. 258-259.

22 CALDERÓN CUADRADO, M.P., La segunda instancia penal, op. cit., p. 164.

23 AGUILERA MORALES, M., GARCÍA COUSO, S., "Las grabaciones defectuosas o fallidas de las vistas...", op. cit., p. 265. 
no siendo vital focalizarlo ${ }^{24 "}$. En este sentido, el derecho al recurso en el orden penal constituye una materialización de la tutela judicial efectiva en la medida en que supone un acceso necesario al segundo grado. Igualmente es una exigencia del derecho de defensa de los justiciables porque solo mediante el recurso podrá corregirse la indefensión sufrida en primera instancia. También, está implícito en el mandato de un proceso con las debidas garantías puesto que las infracciones de las garantías procesales ya sean sustantivas o formales, solo podrán subsanarse mediante el correspondiente ejercicio del recurso.

En cuanto al alcance del derecho al recurso en el orden penal, el Comité de Derechos Humanos de Naciones Unidas, a propósito de la interpretación del artículo 14.5 del Pacto ha señalado que se debe tratar de una revisión íntegra del fallo condenatorio y de la pena impuesta, abarcando tanto las cuestiones de hecho como de derecho. Desde el año 2000 hasta 2005 el Comité de Derechos Humanos de la ONU, ha advertido a España la necesidad de respetar este mandato y, en efecto, estas recomendaciones parecen haber influido en la legislación española tanto en la LO 19/2003 como en la Ley ordinaria por la que se modifican diversas normativas procesales. De ambos textos se deduce una concepción garantista de la segunda instancia configurada como un sistema de garantías de las libertades individuales a través del doble grado de jurisdicción y, se confirma la posibilidad de recurso frente a todas las resoluciones judiciales, sean estas de los Juzgados, Audiencias, Tribunales Superiores de Justicia e incluso las del Tribunal Supremo en el caso de aforados ${ }^{25}$.

Aunque la más reciente legislación se hace eco de este mandato del Comité, y en el orden penal se revisan íntegramente los procesos, con anterioridad era el acta el medio a través del cual el Tribunal Constitucional rompía el principio de soberanía probatoria de la primera instancia y mediante el examen del acta se establecía un auténtico reexamen de las pruebas. Desde luego, el acta es un instrumento especialmente apto para el ejercicio del derecho al recurso, porque permite examinar tanto los requisitos meramente procedimentales

24 YÁÑEZ VELASCO, R., Derecho al recurso en el proceso penal, op. cit., p. 262. 
como los aspectos sustantivos o materiales del proceso. Claro que para que esto sea posible el acta debe ser extensa, minuciosa y comprender todos y cada uno de los resultados probatorios con todo el detalle posible; es decir, no solo si se realizaron o no determinadas pruebas, sino el contenido de dichas pruebas ${ }^{26}$. Como afirma Sáez González: “Un proceso sin fe pública y sin documentación es un proceso encaminado a hacer inefectivo el principio de tutela judicial efectiva. El acta, en consecuencia, es una exigencia indudable del proceso conforme a los principios procesales que marca nuestra Constitución ${ }^{27}$ ".

\section{Defectos en el acta y Lesión del derecho fundamental DE DEFENSA.}

Como se ha indicado, la introducción de los medios audiovisuales en la documentación del juicio oral ha contribuido a mejorar los principios y finalidades inherentes al acta; sin embargo, a pesar de esta notable mejora también se pueden producir problemas eventuales o defectos técnicos que pongan en peligro una exhaustiva documentación del juicio oral. Se debe cuestionar entonces cuáles serían los efectos de una deficiente documentación sobre los derechos procesales de las partes en litigio.

Ciertamente, la grabación de las actuaciones procesales contribuye al mejor desarrollo contradictorio del proceso, fomenta la inmediación física del juez en el juicio y práctica de las pruebas, favorece la confianza de las partes y la fidelidad del acta con las actuaciones ${ }^{28}$; así mismo, contribuye a desarrollar la oralidad del proceso y extiende la publicidad de las actuaciones más allá del acto documentado ${ }^{29}$. Con más precisión escribe Calderón Cuadrado: "Ni qué decir tiene que la grabación de la vista juega un papel decisivo a la hora de comprobar los errores que el juez a

26 SÁEZ GONZÁLEZ, J., El acta del juicio oral..., op. cit., pp. 187-189.

27 Ibidem, p. 192.

28 Así, por ejemplo, la SAP Tarragona 07/02/2017 num. 194/2016 estima el recuso de apelación de la condenada tras el visionado de las pruebas testificales, apreciando error en la valoración de las mismas por la instancia.

29 AGUILERA MORALES, M., GARCÍA COUSO, S., "Las grabaciones defectuosas o fallidas de las vistas...", op. cit., p. 245. 
quo hubiera podido cometer sobre el contenido de la actividad probatoria. Siendo como son los términos de comparación la documentación del acto y la propia resolución judicial, resulta claro que el carácter impersonal y completo del registro audiovisual facilitará notablemente el descubrimiento en la sentencia de este tipo de incorreciones ${ }^{30 "}$.

Ahora bien, esta mejor garantía solo se produce cuando la grabación se ha llevado a cabo sin errores y no siempre es así. Sea por error humano, fallo técnico o electrónico, es posible que o bien, la grabación no llegue a realizarse, o, tan solo se graben algunas actuaciones del juicio, o bien, se grabe la imagen y no el sonido, o, viceversa. En principio, este tipo de errores no tiene por qué afectar a la validez del juicio oral siempre que el secretario judicial esté presente en el momento de la grabación ya que, en este caso, podría continuar la documentación del proceso mediante soporte escrito, que complementaría el acta audiovisual deficiente ${ }^{31}$. Por otro lado, las recientes reformas legislativas en el orden procesal han flexibilizado, cuando no postergado, la necesidad de la presencia del secretario judicial en la grabación del juicio oral y su obligación de transcribir el contenido registrado en la filmación, como demuestra el artículo 230.3 de la LOPJ y el artículo 147 de la Ley 42/2015 de reforma de la Ley de Enjuiciamiento Civil (en adelante LEC) ${ }^{32}$.

Artículo 230.3 LOPJ: "Las actuaciones orales y vistas grabadas y documentadas en soporte digital no podrán transcribirse, salvo en los casos expresamente previstos en la ley".

Artículo 147 LEC: "Las actuaciones orales en vistas, audiencias y comparecencias celebradas ante los jueces o magistrados o, en su caso, ante los letrados de la Administración de Justicia, se registrarán en soporte apto para la grabación y reproducción del sonido y la imagen y no podrán transcribirse”.

30 CALDERÓN CUADRADO, M. P., La encrucijada de una justicia penal tecnológicamente avanzada, Madrid, LaLey, 2011, p. 101.

31 SÁEZ GONZÁLEZ, J., El acta del juicio oral..., op. cit., p. 266. Así, por ejemplo, la STS 31/10/2012 num. 3760/2011; STS 3/10/2019 num. 10183/2019

32 ADAN DOMENECH, F., "Documentación de la actividad procesal y nulidad de actuaciones”, Revista General de Derecho Procesal, n. 30, (2013), p. 20. 
Si a esta situación se añade el hecho de que, generalmente, el secretario judicial valida mediante firma electrónica o telemática la grabación audiovisual del juicio oral y que los defectos en la misma se revelan, normalmente, una vez que ha concluido el juicio; las consecuencias de este cúmulo de errores pueden derivar en la nulidad del juicio, ex artículo 225 LEC al provocarse indefensión.

En el orden civil, por lo general rige el principio de conservación del proceso y la nulidad se decreta únicamente con carácter excepcional, pues debe producirse una efectiva indefensión de parte que ha de ser alegada en el momento procesal oportuno ${ }^{33}$.

En el orden penal, dada su especial naturaleza y la mayor extensión de los derechos del justiciable ${ }^{34}$, la situación es diferente. Como señala Calderón Cuadrado, "el legislador no ha sido ajeno a esta diversidad: como se adelantó, las modificaciones introducidas por la Ley de la nueva oficina judicial respecto a la solicitud de reproducción de lo grabado en la fase de vista del recurso penal no se han trasladado a su homónima civil y ello a pesar de equipararse los sistemas de documentación de las actuaciones orales respectivas ${ }^{35}$ ". Más aun, en el orden penal, cuando la deficiente grabación del juicio oral afecta a la práctica de una prueba de cargo, la dificultad o imposibilidad de revisarla en segunda instancia afectará directamente al derecho al recurso de la parte y a su derecho de defensa, decretándose la nulidad ${ }^{36}$ en virtud del artículo 238.3 LOPJ: "Los actos procesales serán nulos de pleno derecho en los casos siguientes. 3. ${ }^{\circ}$

33 AGUILERA MORALES, M., GARCÍA COUSO, S., "Las grabaciones defectuosas o fallidas de las vistas...", op. cit., p. 251.

34 CALDERÓN CUADRADO, M. P., La encrucijada de una justicia ..., op. cit., p. 147. "no se olvide, es titular [el imputado] de los derechos fundamentales relativos a la presunción de inocencia y a la revisión de la sentencia condenatoria y de la pena impuesta".

Ibidem, p. 148.

36 En este sentido pueden encontrarse numerosa jurisprudencia: SAP La Coruña 28/06/2013 num. 411/2013, SAP Murcia 25/07/2014 num. 97/2014, SAP Madrid, 22/03/2010 num. 434/2009, SAP Gran Canaria 23/12/2016 num. 942/2016, SAP Illes Baleares 25/09/2017 num. 132/2017, SAP Alicante 17/11/2016 num. 1882/2016, SAP Córdoba 10/11/2015 num. 1308/2015, entre las más recientes. En todas estas sentencias del territorio nacional las Audiencias decretaron la nulidad de los juicios previos dados los defectos en la grabación de las actuaciones determinates de la indefensión. 
Cuando se prescinda de normas esenciales del procedimiento, siempre que, por esa causa, haya podido producirse indefensión”. En estos casos, deberá realizarse un nuevo juicio ante un juez distinto para preservar la imparcialidad del juzgador ${ }^{37}$. Decretada la nulidad no podrá recurrirse, pues se retraen las actuaciones al momento inicial y la cuestión de fondo quedará imprejuzgada, es decir, como si no hubiese sido objeto de juicio antes ${ }^{38}$.

Como ejemplo de esta situación se puede encontrar la sentencia del Tribunal Supremo de 11 de julio de 2017, en la que literalmente se afirma: "Todo avance conlleva dificultades de implantación que es necesario afrontar con perspectiva de futuro. Ahora bien, cuando se ven afectados derechos fundamentales de los ciudadanos, como el de tutela judicial efectiva en sus distintas vertientes, o la garantía de presunción de inocencia, es imprescindible minimizar los riesgos hasta prácticamente erradicarlos. De ahí que, en tanto en cuanto no sea posible garantizar un óptimo funcionamiento del sistema, que reduzca los errores a lo meramente anecdótico, es necesario intensificar las cautelas y compatibilizar los nuevos sistemas con otros que, sin frenar el avance tecnológico, garanticen los fines del proceso”. Como señala De Lamo Rubio: nadie puede refrendar la autenticidad e integridad de una grabación hasta que esta no ha concluido, de ahí que la validación por el secretario judicial debe producirse una vez que el acto ha terminado y que, por muy avanzado que sea el sistema, este debe controlar su funcionamiento correcto $^{39}$.

Conviene precisar que no siempre una grabación defectuosa determinará la nulidad de las actuaciones y que se conservará la validez del proceso en los siguientes casos: a) cuando la prueba no documentada no sea determinante para la sentencia; b) cuando se omitan ciertos requisitos formales en la articulación de la pretensión impugnatoria; y c) cuando no se argumenten suficientemente los motivos sobre los que

37 AGUILERA MORALES, M., GARCÍA COUSO, S., "Las grabaciones defectuosas o fallidas de las vistas...”, op. cit., p. 254.

38 ADAN DOMENECH, F., "Documentación de la actividad procesal...", op. cit., p. 23.

39 DE LAMO RUBIO, J., "Justicia digital y nulidad de actuaciones judiciales", Diario La Ley, n. 9042, (2017), p. 5. 
se fundamenta la impugnación, que deberán vincularse las garantías recogidas en el artículo 24 CE y su relación con el derecho a la defensa ${ }^{40}$. En este sentido, la STC 55/2015 señala que no siendo determinantes para la sentencia las pruebas practicadas no se produce indefensión, pues, carecen de relevancia para modificar la relación de hechos probados. Tampoco se vulnera el derecho al recurso, puesto que nada impide al recurrente articular su impugnación apelando a la revisión del juicio, como tampoco se impide su acceso a la segunda instancia penal ni a un proceso justo con todas las garantías. En un sentido similar, la STS 1000/2016 de 17 de enero, descartó una indefensión sustantiva en un supuesto de grabación incompleta y de inexistencia de acta del secretario - porque ni el recurrente expresó que el contenido concreto de las pruebas hubiese sido tergiversado en la motivación que de ellas hizo el tribunal, ni sostuvo que las declaraciones abarcaran extremos esenciales no contemplados por el tribunal.

Siguiendo la enumeración señalada por Adán Doménech, la nulidad de las actuaciones a causa de actas audiovisuales defectuosas procederá en estos supuestos: imposible valoración del material probatorio, imposibilidad de adquirir el conocimiento de la relación jurídica para un nuevo enjuiciamiento, imposibilidad de concretar el razonamiento lógico de las conclusiones de las partes emitidas en la vista del juicio, inexistencia de acta completa consignada por el Secretario judicial como subsanación de la grabación defectuosa y, por último, el desconocimiento de las partes procesales de las consecuencias del acta defectuosa referentes a la defensa de sus intereses ${ }^{41}$.

La reiteración de los errores de grabación en los juicios penales a lo largo del territorio nacional y la consecuente proliferación de recursos ha obligado al Tribunal Supremo a detallar minuciosamente cuál es la posición de la Sala, sintetizando la jurisprudencia sobre esta cuestión la Sentencia de la Sala Segunda del Tribual Supremo 23/07/2019 num. 10389/2018, expresa literalmente en el Fundamento

\footnotetext{
40 AGUILERA MORALES, M., GARCÍA COUSO, S., "Las grabaciones defectuosas o fallidas de las vistas...”, op. cit., p. 254.

${ }^{41}$ ADAN DOMENECH, F., "Documentación de la actividad procesal...", op. cit., pp. 13-21.
} 
de Derecho Primero, punto 5: "una vez constatada la existencia de un defecto de grabación procede valorar a continuación si el mismo es revelador de una verdadera indefensión material, a la vista del tipo de impugnación, la naturaleza de los motivos invocados y las alegaciones que se incluyan en ellos; pero, en todo caso, ha de tenerse presente que: i) las deficiencias en la grabación del juicio oral no alteran los márgenes del recurso de casación marcados por la necesidad de respetar la valoración de la prueba efectuada en instancia, con las garantías que proporciona el principio de inmediación; ii) la deficiente grabación del juicio, no conlleva, en todo caso, indefensión, cuando el Tribunal de casación está en condiciones de evaluar, sin limitación, la corrección del juicio probatorio, en el caso concreto y en atención a las alegaciones del recurso; y iii) sería posible plantearse una indefensión si el recurrente precisa el contenido concreto de las pruebas, datos o elementos no documentados de manera alguna que son incompatibles con lo expresado por los Magistrados en su sentencia y siempre que para resolver el recurso sobre este aspecto sea imprescindible conocer lo acaecido en el juicio no documentado" ${ }^{42}$.

\section{Consecuencias de la repetición del juicio oral.}

Como advierte el acuerdo no jurisdiccional de la Sala Segunda del Tribunal Supremo de 24 de mayo de 2017: "cuando la documentación relativa al juicio oral sea imprescindible para la resolución del recurso, su ausencia en relación con los aspectos controvertidos, que genere indefensión material, determinará la nulidad del juicio oral o, en su caso, la absolución" En estos casos, como se ha mencionado anteriormente, las consecuencias de la nulidad es la retroacción de las actuaciones al momento del señalamiento de la vista oral del juicio (art. 241.2 LOPJ), debiéndose celebrar un nuevo juicio por tribunal diferente y cuyo desarrollo quede debidamente documentado ${ }^{43}$. Ahora bien, debe

42 STS 253/2017 de 6 de abril, STS 734/2010 de 23 de julio, STS 464/2015 de 7 de julio, STS 1000/2016 de 17 enero, STS 529/2017 de 11 de julio, STS $84 / 2018$ de 15 de febrero, entre las más destacadas.

43 STS 11 de julio de 2017. FJ Quinto y Fallo. 
cuestionarse si más allá del tenor legal del artículo 238.3 LOPJ que ordena la nulidad, esta medida es el mejor modo de resolver la situación conflictiva; habida cuenta de que la repetición del juicio supone un coste añadido para los litigantes, para la Administración de Justicia y elude la responsabilidad de la Administración y sus funcionarios en los hechos determinantes de esta nulidad. Sin perjuicio de examinar la incidencia que un nuevo proceso pueda tener sobre el principio de non bis in idem y la seguridad jurídica.

Desde un punto de vista estrictamente teórico-dogmático la nulidad presupone la inexistencia de todo lo actuado, esto es, como si no se hubiese producido nunca; lo que impediría plantearse la vulneración del non bis in idem o cualquier posible afectación a la seguridad jurídica. Desde esta perspectiva, la nulidad mantiene incólumes los principios vertebradores del orden penal, es decir, el principio de legalidad y de judicialidad, porque nunca existió el proceso en el que las deficiencias se detectaron. Igualmente, al no existir jurídicamente el proceso nulo, la confianza ciudadana en la Administración de Justicia y su correcto o normal funcionamiento no se ve mermada, ni perjudicado el valor justicia $^{44}$, como tampoco el derecho a la tutela judicial efectiva ${ }^{45}$.

Desde un punto de vista práctico, declarada la nulidad del juicio por acta defectuosa es claro que la Administración deberá devolver de oficio las cantidades satisfechas (tasas, honorarios, depósitos practicados) por las partes con anterioridad a la celebración del juicio oral (art. 241.2 LOPJ y ex art. 1303 del Código Civil, en adelante CC).

¿Sin embargo, qué ocurriría en el caso de pruebas cuya reproducción en un nuevo proceso fuera imposible, imposibles de practicar o destruidas? El único medio posible de acceso a estas pruebas sería el acta, pero al encontrarse defectuosa o mal grabada resultará que estas piezas de convicción se han perdido. Entonces es evidente que las consecuencias derivadas de una grabación defectuosa ocasionan unos daños económicamente cuantificables, y que estos no quedan reparados por vía de la nulidad. Podría considerarse, entonces, la posibilidad

44 YÁÑEZ VELASCO, R., Derecho al recurso en el proceso penal, op. cit., pp. 124-129.

45 Ibidem, pp. 314-316. 
de plantear la responsabilidad patrimonial de la Administración, ya que el funcionamiento anormal de la Administración de Justicia es un supuesto de responsabilidad objetiva del Estado-juez. Este tipo de responsabilidad pública actúa solamente en el caso de vulneraciones graves del derecho a la tutela judicial efectiva, integrado tanto por el derecho al proceso, como el derecho a que se desarrolle según los parámetros constitucionales y por el derecho al aseguramiento del bien o derecho en litigio ${ }^{46}$. Como recoge González Alonso: "en el Ministerio de Justicia se consideran y tramitan como causas de funcionamiento anormal las dilaciones indebidas, las suspensiones de vistas, el extravío o pérdida de medios probatorios o pruebas de convicción, el extravío de depósitos judiciales, embargos o prisión preventiva o detención indebida por funcionamiento anormal ${ }^{47}$ ".

No cabe duda de que la nueva celebración del juicio supone un coste para las partes, que deberán satisfacer nuevamente las tasas administrativas necesarias para litigar, así como el coste de los honorarios de abogados y procuradores, junto al resto de costas procesales. Más aún, para la Administración de Justicia la celebración de un nuevo juicio supone una carga añadida para la ya saturada práctica jurisdiccional y también un descrédito de la Administración de Justicia para la ciudadanía. Sin prejuicio de la desconfianza en la Administración, estos nuevos costes no serán sino los naturalmente resultantes del acceso a los órganos jurisdiccionales, porque debe tenerse en cuenta que los gastos sufragados en el proceso nulo fueron devueltos. En un primer momento podría cuestionarse si la celebración de un nuevo juicio a causa de la nulidad supone un supuesto de dilaciones indebidas; porque, ciertamente, los sujetos ven pospuestas la resolución de sus pretensiones a un nuevo proceso más o menos lejano en el tiempo. Sin embargo, no se trataría de un supuesto de anormal funcionamiento de la Administración de Justicia; porque, precisamente, el nuevo juicio tendrá lugar para subsanar los defectos que motivaron la nulidad y, en consecuencia, para una mejor garantía y realización de los derechos fundamentales de carácter procesal que asisten a las partes.

46 GONZÁlEZ ALONSO, A., Responsabilidad Patrimonial del Estado en la Administración de Justicia, Valencia, Tirant lo Blanch, 2009, pp. 57-59.

47 Ibidem, p. 58. 
¿Ahora bien, en el caso de pruebas imposibles de practicar en un nuevo proceso, es posible considerar exigible responsabilidad patrimonial a la Administración alegando un funcionamiento anormal de esta? Y si así fuese, ¿quién habría de responder por estos daños: ¿el Estado o el secretario judicial? Aun no ha habido un desarrollo jurisprudencial y casuístico que permita responder a estos interrogantes. Aquí se propone establecer una relación de semejanza entre la responsabilidad por acta defectuosa y la responsabilidad patrimonial de la Administración, cuando se pierden piezas de convicción.

Una base sólida para exigir responsabilidad patrimonial al Estado por funcionamiento anormal de la Administración de Justicia, sería considerar el acta como un medio probatorio de carácter esencial para el ejercicio del derecho al recurso y al haber sido registrada defectuosamente, asimilarlo a un supuesto de pérdida o deterioro de piezas de convicción. Los fundamentos teóricos de esta relación de semejanza deben quedar debidamente argumentados: primero, determinar si el acta del juicio oral puede ser considerada como el único modo de conocer las pruebas de cargo (imposibles de repetir) del proceso declarado nulo; segundo, establecer una relación causal entre los defectos de grabación del acta y la conducta poco diligente del Secretario Judicial.

Es claro que el acta del juicio oral constituye el principal medio de prueba para la sustanciación del recurso y el acceso al segundo grado jurisdiccional. Además, se trata de un medio de prueba de carácter privilegiado, ya que se le presumen las notas inherentes a la fe pública judicial: veracidad, integridad, inmediación, exclusividad y neutralidad ${ }^{48}$. Tampoco cabe cuestionar la relevancia de la documentación procesal a efectos del derecho a la tutela judicial efectiva y a un proceso con las debidas garantías, tanto en lo que se refiere a la posibilidad del recurso a instancias superiores (vocación histórica de la documentación procesal) como para el examen crítico de la motivación judicial y su valoración probatoria ${ }^{49}$. De acuerdo con lo anterior, no es extraño que La STC 55/2015 concluya que: "la documentación de las actuaciones no constituye un requisito de

48 SÁEZ GONZÁLEZ, J., El acta del juicio oral..., op. cit., pp. 91-104.

49 Ibidem, pp. 199-206. 
validez de los actos procesales, sino la prueba auténtica que permite constatar la realidad material de lo actuado".

En cuanto se refiere al establecimiento del nexo causal entre los defectos de grabación del acta y la actitud poco diligente del secretario judicial, parece claro que éste ocupa la función de fedatario y garante de la validez, legalidad e integridad del contenido del acta y si ésta no reúne esas condiciones debe imputársele al mismo. Es decir, que dada la condición de garante que le caracteriza, no será necesario que el acta defectuosa se produzca de manera dolosa o intencionada; bastará probar que el mismo no mantuvo la diligencia debida o infringió su deber de cuidado para deducir objetivamente su responsabilidad. En este sentido, especialmente flagrante puede ser el supuesto de acta videográfica defectuosa validada por el secretario telemáticamente sin estar presente en la vista, posibilidad legalmente prevista ex artículo. 743.2 Ley de Enjuiciamiento Criminal ${ }^{50}$; pues, como sea que los defectos de grabación sólo podrán ser detectados una vez concluida la vista, la más elemental prudencia exige la presencia real del Secretario para controlar su adecuado funcionamiento ${ }^{51}$. La relativa frecuencia con la que ocurren este tipo de incidencias sería suficiente, teniendo en cuenta el enunciado del artículo citado, para motivar la presencia del secretario y el levantamiento de acta sucinta de la vista. Teniendo presente el deber de cuidado que preside la acción del secretario la responsabilidad será imputable al mismo y, aunque inicialmente sea el Estado el encargado de

50 Art. 743. 2 LECrim: “. Siempre que se cuente con los medios tecnológicos necesarios el Secretario judicial garantizará la autenticidad e integridad de lo grabado o reproducido mediante la utilización de la firma electrónica reconocida u otro sistema de seguridad que conforme a la ley ofrezca tales garantías. En este caso, la celebración del acto no requerirá la presencia en la sala del Secretario judicial salvo que lo hubieran solicitado las partes, al menos dos días antes de la celebración de la vista, o que excepcionalmente lo considere necesario el Secretario judicial, atendiendo a la complejidad del asunto, al número y naturaleza de las pruebas a practicar, al número de intervinientes, a la posibilidad de que se produzcan incidencias que no pudieran registrarse, o a la concurrencia de otras circunstancias igualmente excepcionales que lo justifiquen, supuesto en el cual el Secretario judicial extenderá acta sucinta en los términos previstos en el apartado siguiente".

STS 11 julio 2017. 
responder indemnizatoriamente por los daños causados, posteriormente, podrá repetir contra el funcionario poco diligente ${ }^{52}$.

\section{Conclusiones}

Ante este estado de cosas pareciese que los daños producidos con motivo del acta defectuosa darían lugar a un nuevo supuesto de responsabilidad patrimonial del la Administración; pero, aún, debe cuestionarse si estos daños son propiamente antijurídicos, o bien, aunque imputables a la Administración son secuelas negativas, que deben ser soportadas por los ciudadanos (artículo 141.1 Ley Régimen Jurídico de las Administraciones Públicas y del Procedimiento Administrativo Común). Se considera que, en el supuesto singular de nulidad por acta defectuosa y pruebas imposibles de repetir en un nuevo proceso, los daños causados a las partes por la conducta poco diligente del secretario no deben ser soportados por ellas. Primero, porque la frecuencia con la que este tipo de situaciones se produce, impone - a pesar de las previsiones legales que autorizan al secretario a no estar presente - su presencia por imperativo de la prudencia más elemental. Segundo, porque si el secretario hubiese supervisado la grabación, durante o después, podría haber levantado acta sucinta recogiendo el contenido y práctica de estas pruebas.

La situación descrita a lo largo de las páginas precedentes da la razón a las previsiones hechas en su día por el procesalista italiano Chiavario, quien exhortaba a una completa y rigurosa regulación del uso de los medios audiovisuales en la grabación y documentación del proceso judicial, así como para su uso argumentativo en procesos posteriores. En definitiva, se hace necesario un auténtico cuerpo o sistemas de normas ad hoc, una infraestructura y organización adecuada para la conservación y reproducción de estas grabaciones y el establecimiento de un régimen de responsabilidad para los técnicos de justicia encargados de la grabación ${ }^{53}$. La impresión general parece ser que tras las sucesivas

52 GONZÁlEZ ALONSO, A., Responsabilidad Patrimonial..., op. cit., p. 93.

53 CHIAVARIO, M., "O impacto das novas tecnologias: os direitos do individuo e o interesse social no processo penal", Revista Portuguesa de Ciência Criminal, n. 7, (1997), p. 389-390. 
reformas tendentes a la instauración del acta audiovisual aún quedan puntos oscuros o problemas por resolver, que hasta el momento han obtenido respuesta en la jurisprudencia del Tribunal Supremo; pero que exigiría una reformulación de los textos legislativos con la finalidad de arrojar luz sobre la cuestión y establecer nítidamente las reglas de su uso y las garantías de su corrección.

\section{Bibliografía}

ADAN DOMENECH, F., "Documentación de la actividad procesal y nulidad de actuaciones”, Revista General de Derecho Procesal, n. 30, (2013).

AGUILERA MORALES, M., GARCÍA COUSO, S., "Las grabaciones defectuosas o fallidas de las vistas y juicio: transcendencia procesal y constitucional”, Nuevas tecnologías y derechos fundamentales en el proceso, Aranzadi, Cizur Menor, 2017.

CALDERÓN CUADRADO, M.P., La segunda instancia penal, Aranzadi, Cizur Menor, 2005.

CALDERÓN CUADRADO, M.P., La encrucijada de una justicia penal tecnológicamente avanzada. Sobre la grabación de las vistas, los recursos y la garantía de inmediación, Madrid, La Ley, 2011.

CHIAVARIO, M., "O impacto das novas tecnologias: os direitos do individuo e o interesse social no processo penal”, Revista Portuguesa de Ciência Criminal, n. 7, (1997).

DE LAMO RUBIO, J., “Justicia digital y nulidad de actuaciones judiciales”, Diario La Ley, n. 9042, (2017).

GONZÁLEZ ALONSO, A., Responsabilidad Patrimonial del Estado en la Administración de Justicia, Tirant lo Blanch, Valencia, 2009.

JIMÉNEZ ASENSIO, R., "Administración de Justicia y Nuevas Tecnologías: líneas de evolución de un proceso abierto”, Nuevas Políticas Públicas: Anuario multidisciplinar la modernización de las Administraciones Públicas, n. 1, (2005).

LOMBARDÍA VILLALBA, A., "Nuevas Tecnologías y Administración de Justicia”, Foro de Actualidad Uría Menéndez, n. 30, (2011).

MEDINA MORALES, D., “Administrar justicia en la era tecnológica”, Persona y Derecho, n. 78, (2018). 
SÁEZ GONZÁLEZ, J., "Una nota histórica: primeras noticias sobre la actividad de documentación procesal en nuestro derecho”, Justicia, n. 95, (1993).

SÁEZ GONZALEZ, J., "Propuestas sobre los contenidos de la documentación audiovisual de los juicios orales. Papel del secretario judicial”, Revista vasca de derecho procesal y arbitraje, n. XXI.1, (2009).

SÁEZ GONZÁLEZ, J., El acta del juicio oral en el proceso penal, Bosch, Barcelona, 1996.

SÁNCHEZ PARELLADA, J., "El acta del juicio oral en el proceso penal y las nuevas tecnologías”, Actualidad penal, n. 1, (2003).

VIDAL, E., “Los derechos humanos de tercera generación”, en MEGÍAS QUIRÓS, J. J., Manual de Derechos Humanos, Aranzadi, Cizur Menor, 2006.

YÁÑEZ VELASCO, R., Derecho al recurso en el proceso penal, Tirant lo Blanch, Valencia, 2001. 


\section{Informações adicionais e declarações dos autores (integridade científica)}

Declaração de conflito de interesses (conflict of interest declaration): a autora confirma que não há conflitos de interesse na realização das pesquisas expostas e na redação deste artigo.

Declaração de autoria e especificação das contribuições (declaration of authorship): todas e somente as pessoas que atendem os requisitos de autoria deste artigo estão listadas como autores; todos os coautores se responsabilizam integralmente por este trabalho em sua totalidade.

Declaração de ineditismo e originalidade (declaration of originality): a autora assegura que o texto aqui publicado não foi divulgado anteriormente em outro meio e que futura republicação somente se realizará com a indicação expressa da referência desta publicação original; também atesta que não há plágio de terceiros ou autoplágio. 


\section{Dados do processo editorial}

(http://www.ibraspp.com.br/revista/index.php/RBDPP/about/editorialPolicies)

- Recebido em: 10/07/2019 Equipe editorial envolvida

- Controle preliminar e verificação de plágio: 12/07/2019

- Avaliação 1: 13/07/2019

- Editor-chefe: 1 (VGV)

- Revisores: 3

- Avaliação 2: 22/07/2019

- Avaliação 3: 18/08/2019

- Decisão editorial preliminar: 22/10/2019

- Deslocamento ao V6N1: 22/10/2019

- Retorno rodada de correções 1: 21/11/2019

- Decisão editorial preliminar 2: 09/12/2019

- Retorno rodada de correções 2: 11/12/2019

- Decisão editorial final: 15/12/2019

\section{COMO CITAR ESTE ARTIGO:}

RAMIREZ BENAVANTE, Maria Dolores. La influencia de las nuevas tecnologías en la documentación del proceso penal español. Revista Brasileira de Direito Processual Penal, Porto Alegre, vol. 6, n. 1, p. 397-420, jan./abr. 2020. https://doi.org/10.22197/rbdpp.v6i1.256

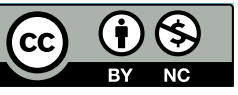

Esta obra está licenciada com uma Licença Creative Commons Atribuição-NãoComercial 4.0 Internacional. 